\title{
Rebecca Bergman: An International Nurse Leader (1919-2015)
}

\author{
Greer Glazer ${ }^{1 \star}$, Laura Startsman ${ }^{2}$, and Mally Ehrenfeld ${ }^{3}$ \\ ${ }^{1}$ Dean of the University of Cincinnati College of Nursing, US. \\ ${ }^{2}$ Clinical Program Developer UC Health, University of Cincinnati \\ US. \\ ${ }^{3}$ Mally Ehrenfeld, Associate Professor and Head of the School \\ of Health Professions, Sackler Faculty of Medicine, Tel Aviv \\ University, Israel.
}

\author{
*Corresponding author \\ Greer Glazer, Dean of the University of Cincinnati College of Nursing, \\ US, E-Mail: greer.glazer@uc.edu.
}

Submitted: 07 July 2017; Accepted: 11 July 2017; Published: 14 July 2017

\begin{abstract}
Glazer, Ehrenfeld and Flanagan write to introduce a renowned nurse leader in Israel, Rebecca (Becky) Bergman, relatively unknown to nurses in the United States and elsewhere. Becky made a lasting impact on the nursing profession and her story will undoubtedly inspire nurses at any and every stage of their professional career. Her journey as a nurse leader demonstrates leadership, risk-taking and creativity, effective communication, inspiration and a clear vision to change the trajectory of the nursing profession in Israel and around the world. As the first nurse to be awarded the Israel prize (the nation's highest honor), she broke down international, interdisciplinary and interprofessional barriers by accomplishing several feats including: becoming a World Health Organization (WHO) Consultant, Vice President for the International Council of Nurses (ICN), Chief Nurse for the American Jewish Joint Distribution Committee, establishing Israel's first academic nursing program and supervising more than 5,000 beds at four hospitals.
\end{abstract}

\section{Introduction}

Leadership in nursing is critical at this time. Increased communication has been made possible through recent achievements in technological globalization. The healthcare and educational systems are rapidly adapting to models enabled by technology, based around evidence and competency training, and focused on meeting the needs of diverse populations. As healthcare shifts its central focus to the patient, so is education centering on the student. A collaborative, team-based approach is the surest path to interdisciplinary practice and interprofessional education. Partnerships between American and international hospitals and universities are becoming the expectation, not the exception. Whether between universities, professions, or nations, these partnerships begin with leaders.

Despite the current trend of globalization, there is a paucity of literature of worldwide nursing leaders and we have yet to routinely include them in our educational curricula. In general, we learn about nursing leaders from the United States, but rarely others. International nursing leaders are important role models in the development of leadership capability. Nurses teach and learn through personal examples; perhaps we find it easier to remember stories than generic case studies. Without the stories of international nursing leaders, we remain ignorant of their message. This omission is a huge mistake. In this article, the authors attempt to introduce a renowned nurse leader in Israel, relatively unknown to nurses in the United States and perhaps elsewhere. Nurse leaders at any stage in their professional career may find inspiration in her story.

J Nur Healthcare, 2017
The first author met Dr. Rebecca 'Becky' Bergman during her Fulbright to Israel in 1998. Although Becky had retired as the Dean of Tel Aviv University's School of Nursing, she was actively involved in mentoring doctoral students. Becky graciously invited the first author to her home weekly for dinner and conversation while attending to her husband, Shimon. During these times, Becky exhibited her great compassion and unabiding love for Shimon as well as reveled the author with stories of her phenomenal nursing career. Becky's great humility, focus on others and love for Nursing and Israel were pervasive themes from these conversations.

\section{Background}

In 1936, Rebecca Lyons immigrated with her family to Israel from Canada at the age of 17. She began her nursing education at the Hadassah Hospital in Jerusalem and enrolled in a post-basic program in midwifery. Her clinical experience was developed in the American Zone in Germany, in refugee camps in Haifa, Egypt, and Palestine, and in Israeli army hospitals. She received her baccalaureate degree from New York University in 1952 and an M.A. in public health nursing the next year. From 1952-1961, Becky was the director of nursing for Malben, a 5,000-bed, fourfacility healthcare system that specialized in elderly and disabled new immigrants in Israel. She completed her nursing education doctorate in 1963 at Columbia University's Teachers College, making her the first doctoral-prepared nurse in Israel. She taught at the Hadassah Hebrew University in Jerusalem and at Tel Aviv University, where she established Israel's first academic nursing program. Along with her husband, Professor Shimon Bergman, Becky made many advances in delivery of gerontological care. 
Internationally, she served as vice president for the International Council of Nurses (ICN) for eight years, as a member of the ICN professional services committee, and as a World Health Organization (WHO) consultant. She helped develop the international ethical code of nurses. Becky was the first nurse to be awarded the Israel prize, the nation's highest honor, and gave her prize money to support research in gerontology. She used her numerous publications to bring attention to nursing on a local, national, and international level. Becky is known as the mother of modern nursing in Israel, but her achievements in leadership and collaboration have reached nurses around the world.

Interpersonal and Communication Effectiveness

Throughout her lifetime, Becky's behavior was consistent. She demonstrated excellence and a willingness to make the best of every situation, looking at the positive side. In 1946-1948, Becky cared for holocaust survivors in Germany and gave hope to family members who had no information on their loved ones. At this time, she followed her role as a public health nurse to prepare pamphlets and translated existing materials to Yiddish. Since there were no other nurses, she opened special quick courses for nurse aides and asked survivor physicians and nurses to help. When working with refugees in a field hospital without a formal translator, she used pantomime to teach how to wash hands and keep hygiene, decrease fevers, and how to deal with symptoms and to identify deterioration of symptoms.

A prolific writer, Becky published her research findings and changed the approach of the nursing profession-prior to her influence, to our knowledge, Israeli nurses rarely read or wrote publications. She propelled nursing's role in the field of gerontology, starting with good interpersonal relationships and the right people in the right places. She pulled nurses into social and professional groups when she observed stagnation and a lack of engagement. Becky believed that in partnership with other professions, nursing can lead changes in healthcare by choosing the right people and motivating them to learn and do. The way Becky communicated with other professionals led them to follow her example. She possessed the knack of how to approach people, to approach the right people, and to say the right thing in the right place at the right time. The message was never herself; it was that the Israeli public needed nursing. She was interested in achieving quality healthcare, not personal advantage.

\section{Risk-taking and Creativity}

Becky's willingness to take risks became apparent at a young age, when she rescued a drowning boy on her seventeenth birthday. As she told the story, she chose nursing as a profession because she knew that she wanted to help others. She made that choice over and over during her life. Her courage was remarkable. During the Second World War she helped in an absorption center in Haifa for immigrants from North Africa, and she used her creativity to make the most of her limited resources. In the Sinai desert, Becky was in charge of two hundred beds in a British airplane hangar; she and one other nurse were the sole caregivers during a measles outbreak. Instead of feeling overwhelmed, she immediately began to teach basic hygiene and techniques to those willing to learn.

In 1946, Becky was made the Chief Nurse for the American Jewish Joint Distribution Committee (JDC) in Munich, Germany. At the time, she was also the only nurse. Along with a secretary, a social worker, and a driver, Becky used rooms and empty houses as clinics to provide care to survivors unwilling to go to the official health centers. Becky and her team occupied facilities and used supplies that had once belonged to Nazis. In 1948, she volunteered to escort 83 orphaned children on a fourteen-day sea voyage from North Africa to Canada. She was the only staff person and she was a second choice: the original escort had suffered a heart attack.

Becky stated that she was underprepared to start the first academic nursing program in Israel. However, she knew that there was a need and she was willing to help, a recurring theme. She independently raised the point that nurses need to be creative in order to be excellent in the field. In 1989, Tel Aviv University established an award for creativity and innovation in her name.

\section{Self-Knowledge}

For those not lucky enough to have met her in person, Becky's warmth and optimism comes through her writing. She always wanted to see the best in others and was dismissive of gossip. She was engaging and participated fully in life. Although she likely achieved more than any other nurse in Israel, she remained humble and self-deprecating. She despaired over her poor spelling and stated that sometimes she has had difficulty understanding other cultures because she was 'spoiled'. She knew that she was the only one or one of the few who was able to write scientifically and publish, so she took a group of nurses under her wing. Leading by example, she taught them how to publish. She involved her colleagues and students in her research.

Her sense of altruism and helping others was not limited to empowering nurses and caring for patients. Becky changed her career path to psychogeriatric care after her oldest sister Molly's battle with Alzheimer's disease. Becky joined her husband Shimon Bergman, an international expert and scholar in gerontology, in researching and advocating for this population. When Shimon later began his own fight with Alzheimer's, Becky became even more determined to find answers.

\section{Inspiring and Leading Change}

An excellent motivator knows how to encourage others to move forward and get to the right place. A visionary has the ability to see the need for things before others. Becky was the extraordinary person who could do both. She had not worked in a hospital for seven years when she came back to Jerusalem after the war, so she asked to work in a hospital ward before accepting the administrative role of Head Nurse at the military hospital. She was very proud of the numerous nurses who were once patient care aides; she established pipelines in Malben and wherever she found a need. She advocated for a psychogeriatric professional nurses' association that responded to patient care needs and to the educational aspirations of the nurses. With her aid, the association was founded and she became part of the original central committee. She was gratified by their achievement of specialty sections focusing on improvement of clinical practice and educational issues.

Becky always told young people that they are the future. She recognized that she would not be around forever, so she needed to prepare the next generation for their role. It is a good thing that she followed through on this since she passed away at the age of 95 in July, 2015. Instead of a master/slave dynamic, she wanted to share: she used a teacher and co-teacher model so that the 
junior partner would be able to lead eventually. She never pursued a hierarchical pattern. She liked to see others succeed, saying that 'no one is jealous of his students and sons'. She gave her colleagues the feeling that she was sharing with them and learning from them. She wanted everyone to believe that they could be a source of inspiration. She gave more than a sense of 'I will pour my knowledge into you and you will take from me'. She was able to listen to everyone and believed that she could learn from anyone. She was always dedicated to finishing the job as an equal partner, never too tired to work with others. She required as much from herself as was required from others.

\section{Strategic Vision}

Becky's strategic vision began early in life, influenced by her early experiences. She would say that she had both legs on the earth but her mind was 'up there'. She was an extensive reader at a young age and knew how to integrate her own knowledge with a prediction of what would be. She changed nursing education to create a balance of power with physicians and other health professions. She thought about the big picture, looked at the overall situation and not just the details - although she knew that in practice, little things and details play a real role. Becky believed that policy should not be developed in a vacuum but in an interdisciplinary partnership. On one level, she actively sought out professional relationships with members of other healthcare professions. She also took a leading role in international work, serving with WHO and as the vice president for ICN.

At Malben, Becky supervised more than 5,000 beds at four hospitals: there were 680 beds for chronic patients and 850 beds for tuberculosis patients. She helped initiate workshops for rehabilitating blind and disabled young people and psychiatric patients. Becky had the autonomy at Malben to pioneer a model of empowerment and professional development. With a better understanding of chronic care needs, Becky knew that the future of Israeli healthcare would be dependent on an educated nursing workforce. After Becky earned her doctorate in nursing, she taught for five years at Hadassah Hebrew University's School of Public Health, commuting two hours one way, five or six days a week. She left in 1967, possibly frustrated by Hadassah's slow progress in opening a university-level nursing program. In 1968, Becky opened the first academic nursing school at Tel Aviv University and chaired the department for the next eight years. She insisted that nursing students be held to the same standards as those pursuing other majors: academic course load, graduation standards, and identical requirements for faculty positions (Page, 1998). Her attention to details and to standards was instrumental to raising the profile of nursing in Israel.

\section{Conclusions}

Nursing leaders are not born: leadership is a lifelong journey. Becky is a perfect example of a nurse leader who fought to break down barriers on international, interdisciplinary, and interprofessional levels. Her story may help other nurses to see their own path. Many other nurse leaders have fought the same battles; their stories have yet to be told. If these leadership stories are shared, our eyes might be opened to a newly visible global community of healthcare providers and educators [1-21].

\section{References}

1. BERGMAN R (1998) "Rebecca Bergman, RN, EdD, retired professor, University of Tel Aviv, Israel. Interview by
Beverley Page", Canadian oncology nursing journal = Revue canadienne de nursing oncologique 8: 269.

2. BERGMAN R (1996) "Odyssey of a project to improve psycho geriatric nursing care", International nursing review 43: 26.

3. BERGMAN R (1990) "Thoughts on the future of nursing", Journal of advanced nursing 15: 865-866.

4. BERGMAN R (1988) "Omissions in nursing research: another look", International nursing review 35: 165.

5. BERGMAN R (1986) "Nursing in a changing world", International nursing review 33: 110.

6. BERGMAN R (1984) "Omissions in nursing research", International nursing review 31: 55.

7. BERGMAN R (1977) "Sex discrimination in nursing in Israel: male or female lib?", Journal of advanced nursing 2: 533-541.

8. BERGMAN R (1975) "Nursing manpower: issues and trends", The Journal of nursing administration 5: 21.

9. BERGMAN R, GRIEF L, OZER S (1976) "The practicum-a learning experience in integration and change", Journal of advanced nursing 1: 197-208.

10. BERGMAN R (2002) "Interview with Rebecca Bergman. Interview by Anne J. Davis", Nursing ethics 9: 3.

11. BERGMAN R (1997) "Contribution of academia to nursing practice in Israel”, Nurse education today 17: 292-296.

12. BERGMAN R (1994) "Editorial", Journal of Clinical Nursing 3: 195-196.

13. BERGMAN R (1986) "Jan forum Academization of nursing education: the Israeli experience", Journal of advanced nursing 11: 225-229.

14. BERGMAN R (1985) "Nurses as a social force", Journal of advanced nursing 10: 197-198.

15. BERGMAN R, SHATZMAN H, DANON A (1982) "Followup study of the Tel Aviv University nursing graduates", International journal of nursing studies 19: 79-88.

16. BERGMAN R, SHAVITT N, DITZIAN I, MELAMED Y (1975) "Work-life of the Israeli registered nurse", International journal of nursing studies 12: 133-168.

17. DOTAN M, KRULIK T, BERGMAN R, ECKERLING S SHATZMAN H (1986) Role models in nursing, England.

18. EHRENFELD M, BERGMAN R, KRULIK T (1993) "Final requirement for a Master's Degree in Nursing: health care policy and its implementation", Journal of nursing management 1: 143-147.

19. EHRENFELD M, BERGMAN R, ZIV L (1992) “Academia-a stimulus for change", International nursing review 39: 23.

20. EHRENFELD M, ZIV L, BERGMAN R (1993) "From diploma to degree: Follow up of R.N.-B.A. graduates of Tel Aviv University", International journal of nursing studies 30: 81-90.

21. BERGMAN R (1999) "Almost 80. aged population: Expectations and roles", International journal of nursing practice 5: 50 .

Copyright: (C2017 Greer Glazer. This is an open-access article distributed under the terms of the Creative Commons Attribution License, which permits unrestricted use, distribution, and reproduction in any medium, provided the original author and source are credited. 